\title{
REVISTAMARACANAN
}

\section{História Regional: novas perspectivas}

\author{
Regional History: new perspectives
}

Apresentação

Isadora Tavares Maleval*

Universidade Federal Fluminense

Campos dos Goytacazes, Rio de Janeiro, Brasil

Cláudia Atallah**

Universidade Federal Fluminense

Campos dos Goytacazes, Rio de Janeiro, Brasil

Susana Cesco ${ }^{* * *}$

Universidade Federal do Estado do Rio de Janeiro Rio de Janeiro, Rio de Janeiro, Brasil

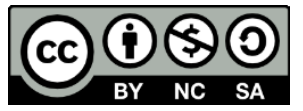

\footnotetext{
* Professora Adjunta da Universidade Federal Fluminense, Campos dos Goytacazes, Instituto de Ciências da Sociedade e Desenvolvimento Regional, Departamento de História. Doutora, Mestre e graduada em História pela Universidade do Estado do Rio de Janeiro. E-mail: isadoramaleval@gmail.com

(iD) http://orcid.org/0000-0003-4882-7907

(9) http://lattes.cnpq.br/5004479701596418

** Professora Adjunta da Universidade Federal Fluminense, Campos dos Goytacazes, Instituto de Ciências da Sociedade e Desenvolvimento Regional, Departamento de História. Professora do Programa de Pós-graduação em História Social da Universidade do Estado do Rio de Janeiro, Faculdade de Formação de Professores. Doutora em História pela Universidade Federal Fluminense; Mestre e graduada em História e Especialista em História do Brasil pela Universidade do Estado do Rio de Janeiro. E-mail: clauatallah@gmail.com

(iD) http://orcid.org/0000-0001-5298-9939 (6) http://lattes.cnpq.br/2918940954094400

*** Professora Adjunta da Universidade Federal do Estado do Rio de Janeiro, Escola de História. Professora do Mestrado Profissional em Ensino de História da Universidade Federal do Estado do Rio de Janeiro. Doutora em História Social pela Universidade Federal do Rio de Janeiro; Mestre e graduada em História pela Universidade Federal de Santa Catarina. E-mail: susanacesco@gmail.com

(iD) http://orcid.org/0000-0002-1357-3743

(9) http://lattes.cnpq.br/1534977452527340
} 
A historiografia recente interpreta "região" como um conceito polissêmico, não apenas ligado a recortes espaciais, construídos por entidades político-administrativas, tais como os Estados-nacionais, como também a questões de identidade e de representação. O presente número da Revista Maracanan traz o dossiê "História Regional: novas perspectivas", aqui vislumbrada como um campo de pesquisa em franco desenvolvimento, partindo de problemáticas concernentes às relações entre espaço físico e espaço social, referendando que toda divisão regional parte de uma definição política. Os estudos aqui apresentados ressaltam a importância de estudos sobre o Brasil em suas múltiplas diversidades e abordagens, que vão além das esferas de poder mais tradicionais. A região também é percebida em sentido ampliado, evocando o campo das lutas simbólicas, a partir do qual, portanto, tornar-se-ia possível investigar aspectos relativos aos debates sobre identidade(s) e memória social.

Diante disso, o dossiê "História Regional: novas perspectivas" reúne trabalhos que partem da perspectiva da história regional aqui explicitada, sem restrições temporais ou epistemológicas, permitindo um diálogo polissêmico e original. Inicialmente apresentamos duas entrevistas sobre História Regional como campo de estudos. As professoras Alessandra Izabel de Carvalho e Maria Silva Leoni falam de suas trajetórias, de como entendem e trabalham com História Regional e analisam as potencialidades e dificuldades da área no Brasil e na Argentina, respectivamente.

Essas entrevistas apresentam o debate que segue com o primeiro artigo de Maria Alice Ribeiro Gabriel intitulado "'A doçura que envolve': a culinária brasileira do Nordeste em Baú de Ossos". Nele a autora faz uma análise da obra do médico e memorialista brasileiro Pedro da Silva Nava, destacando o valor histórico das referências do autor sobre alimentos, em especial a cozinha regional nordestina no século XIX e princípios do século XX. O artigo apresenta uma análise histórico-comparativa para examinar os temas relativos à alimentação e à culinária que emergem de episódios biográficos sobre a família Nava, além de aspectos culturais e sociais de pratos populares e tradicionais do Nordeste brasileiro.

O segundo artigo, de autoria de Clovis Antonio Brighenti \& Osmarina de Oliveira, intitulado "Conflitos territoriais como espaço de disputas entre memória e história: Análise de processos judiciais da Itaipu Binacional contra os Guarani no Oeste do Paraná" desloca o debate sobre região para o sul do Brasil e, através da análise de algumas ações judiciais envolvendo a disputa por terra entre o povo Guarani e o Estado, os autores analisam um discurso construído em torno de elementos que confluem para desconsiderar a história Guarani e desconstruir a memória da ocupação territorial regional, apresentando o estado atual do debate sobre o tema.

O artigo de Fernando Vojniak, "Cultura escrita na Fronteira Sul: Uso políticos da escrita entre os Kaingang" dá continuidade ao debate envolvendo indígenas e questões regionais ao analisar os temas da cultura escrita e das práticas intelectuais indígenas, campos 
ainda pouco explorados pela historiografia. O foco está na apresentação panorâmica das possibilidades de análise em perspectiva histórica das práticas intelectuais e dos usos políticos da escrita entre os indígenas, especialmente os Kaingang.

O quarto artigo é de Marcelo Ferreira Lobo \& Aline de Kassia Malcher Lima, intitulado "Jacobinos da Amazônia: Nacionalismo, trabalho e violência no Pará (1890-1920)". Nele os autores analisam as tensões entre nacionais e estrangeiros em Belém do Pará nas primeiras décadas da República. Para os autores, a presença significativa de imigrantes, em grande parte portugueses, na cidade de Belém, proporcionou o acirramento de tensões étnicas, onde nacionalismo transfigurou-se em antilusitanismo e servem que gancho para o estudo da difusão de ideias nacionalistas entre os anos de 1890 a 1920 no Pará e as implicações no mundo do trabalho amazônico.

O quinto artigo é "Sobre os Dízimos e os Direitos de Saída na São Paulo Provincial" de Camila Scacchetti \& Luciana Suarez Galvão e busca quantificar a trajetória ascendente do dízimo, posteriormente denominado direitos de saída, nas finanças públicas paulistas durante o século XIX. Para as autoras, com essa análise documental é possível traçar um paralelo entre a evolução cafeeira e as expectativas arrecadatórias provenientes do imposto incidente sobre a exportação na região de São Paulo.

$\mathrm{Na}$ sequência, "História regional sob a perspectiva dos processos civilizadores: possibilidades de pesquisa a partir do caso de Monte Alegre - PR", artigo de Ana Flávia Braun Vieira \& Miguel Archanjo de Freitas Junior, traz o debate sobre a cidade-empresa de Monte Alegre (atual município de Telêmaco Borba, Paraná), de propriedade das Indústrias Klabin. Os autores buscam compreender como a região conhecida como sertões do Tibagi se tornou uma referência para a industrialização e urbanização nacional de meados do século XX e o fazem analisando o conteúdo das crônicas de Hellê Vellozo Fernandes, publicadas no jornal O Tibagi entre 1948 e 1964. A partir desses textos são identificadas e apresentadas as sensibilidades que orientaram o processo de civilização naquela formação social, as esferas da vida às quais as publicações eram dirigidas e os processos de adequação comportamental e as ações de resistência.

Em "De Straßburg a Strasbourg: Marc Bloch, Lucien Febvre e o nascimento dos Annales" Jougi Guimarães Yamashita nos apresenta uma discussão bastante interessante sobre a importância da Universidade de Estrasburgo no processo de criação da revista Annales d'Histoire Économique et Sociale, liderado por Marc Bloch e Lucien Febvre. Estabelecendo uma relação alvissareira com a proposta do dossiê, o autor estabelece diálogos entre as estratégias políticas de reconhecimento da Alsácia como região francesa a partir de 1919, após o domínio alemão de quase quarenta anos. A partir da pesquisa realizada em algumas revistas históricas, Yamashita propõe uma análise dos esforços dos renomados editores em afirmar a região em questão como francesa, bem como a relação desse processo com a editoração dos Annales.

A seguir, Samira Peruchi Moretto, em seu artigo intitulado "O desmatamento e reflorestamento no Oeste de Santa Catarina nas décadas de 1960 e 1970", propõe um estudo 
sobre o desmatamento do estado de Santa Catarina e as práticas empreendidas, sem preocupações ambientais, durante as décadas de 60 e 70 do século XX, de projetos considerados pela autora como "de cunho imediatistas". A historiografia mais recente tem se aprofundado nas relações entre a História Ambiental e a História Regional e a pesquisa apresentada pela autora em seu artigo demonstra com êxito esses debates, a partir de uma base documental bastante diversificada.

O décimo artigo que compõe o dossiê se intitula "Os indesejados da seca: a imagem do sertanejo desde as narrativas da Revista Instituto do Ceará ao Campo de Concentração do Alagadiço (1877-1915)", de autoria de Leda Agnes Simões de Melo \& Camila de Sousa Freire, é um estudo sertanejo. Seu mote é a criação do primeiro campo de concentração do estado, o campo do Alagadiço, na seca do ano de 1915. Sua intenção é propor uma análise do discurso construído, na época, pelo Instituto do Ceará e por uma elite em torno dessa instituição, sobre a região, o pioneirismo cearense e a abolição da escravatura.

O próximo artigo que apresentamos é intitulado "No Asilo e no orfanato: crianças pobres e doentes em Goiás na primeira metade do século XX", de autoria de Rildo Bento de Souza \& Lara Alexandra Tavares da Costa. O trabalho toma como foco duas instituições de caridade leigas para crianças pobres e doentes com o objetivo de realizar um estudo sobre as relações de poder na cidade de Goiás, relacionando as estruturas políticas regionais com as formas de caridade assistencial adotadas pelas elites da cidade.

A seguir temos um artigo de autoria de Raimundo Hélio Lopes, "O general do Norte: Juarez Távora e o movimento pelo seu generalato no imediato pós-30". O autor, através de pesquisas realizadas na documentação do arquivo pessoal de Juarez Távora e no acervo de imprensa da região norte, analisa as estratégias adotadas por Juarez Távora e seu grupo para tomar e demarcar a região, na conjuntura política do pós Revolução de 1930.

"Os agentes não humanos na construção da paisagem da Cidade-Parque: História da Arborização de Brasília-DF (1960-1980)", assinado por Marina Salgado Pinto \& José Luiz de Andrade Franco é mais um estudo que se vale das relações estabelecidas pela historiografia recente entre História Regional e História Ambiental. É apresentada uma análise feita sobre o processo de arborização de Brasília nas décadas de 1960 e 70. Considerando uma "visão utilitarista da natureza", os autores problematizam a influência da mídia, dos agentes políticos e dos especialistas envolvidos no projeto na formação de um espaço urbano que controlasse a paisagem nativa e atendesse às demandas de controle dos poderes constituídos, harmonizando-as.

Fechando o nosso dossiê temos o artigo intitulado "O papel do Instituto Histórico na construção de memórias sobre a Baixada Fluminense (1971-1985)" de Eliana Santos Laurentino \& Rui Aniceto Fernandes, analisa como o Instituto Histórico da Câmara de Duque de Caxias (RJ), foi útil para edificar uma memória de "Progresso" para o município, nos anos 1970. Explorando os usos do espaço físico do próprio Instituto em comemorações oficiais os autores sustentam que a memória não se constrói livremente, mas é alimentada por 
arquivos, aniversários e celebrações que foram usadas, nesse caso, para favorecer o diálogo com o regime político vigente.

Priscila Gomes Correa \& Aline Farias de Souza são as autoras de "Política e Região: a Bahia da Modernização Conservadora e o primeiro governo estadual de Antonio Carlos Magalhães". A nota de pesquisa, adjunta ao dossiê, apresenta um estudo baseado nos diálogos possíveis entre a História Regional e a História Política. Para tal, é feito uma análise do processo de construção do que as autoras chamaram de "região da Bahia da Modernização Conservadora", durante o primeiro governo de Antônio Carlos Magalhães no estado (19711975) e das mudanças provocadas no território baiano.

$\mathrm{Na}$ seção de artigos livres os trabalhos estão publicados "Quando os súditos se convertem em soldados: O pacto político ao Norte e ao Sul da América Portuguesa" de Christiane Figueiredo Pagano de Mello; "A narrativa poética de Joaquim Alves da Silva: polícia versus jagunços no oeste; e, sudoeste do Paraná" de Claércio Ivan Schneider; e, "A administração dos bens confiscados dos Jesuítas na Capitânia de São Paulo, 1760-1782" de Ilana Peliciari Rocha.

Por fim, este número é fechado com a tradução de um texto seminal de Martin Jay, professor Emérito da University of California-Berkeley. '"Ei! Qual é a grande ideia?': ruminações sobre a questão da escala na História Intelectual" discute sobre este ramo da historiografia a partir de uma proposta metódica que reconhece a ambiguidade semântica dos conceitos, por meio de uma leitura que considera a longa duração. O exercício de crítica do autor surge como uma resposta e alternativa à chamada História das Ideias tradicional.

Basta agora convidar o leitor a navegar no sumário do número 26 da Revista Maracanan. Desde já, desejamos boas leituras!

As organizadoras. 
